Supporting Information

\title{
Upscaling 3D Engineered Trees for Off-Grid Desalination
}

\author{
Sunxiang Zheng ${ }^{\mathrm{a}}$, Meiqi Yang ${ }^{\mathrm{a}}$, Xi Chenª, Claire E. White ${ }^{\mathrm{a}}$, Liangbing Hu${ }^{\mathrm{b}}$, Zhiyong \\ Jason Ren ${ }^{*}$ \\ aDepartment of Civil and Environmental Engineering and the Andlinger Center for \\ Energy and the Environment, Princeton University, Princeton, NJ 08544, USA \\ ${ }^{b}$ Department of Materials Science and Engineering, University of Maryland, College \\ Park, MD 20742, USA
}

Number of pages: 15

Number of figures: 14

Number of Tables: 1

\section{Characterization of the skin layer of engineered trees}

The cross-sectional SEM image reveals that during the surface carbonization process, the outermost cellulose walls collapsed due to the high temperature and slight pressure by hand pressing. The decomposed cellulose walls formed a continuous porous structure.

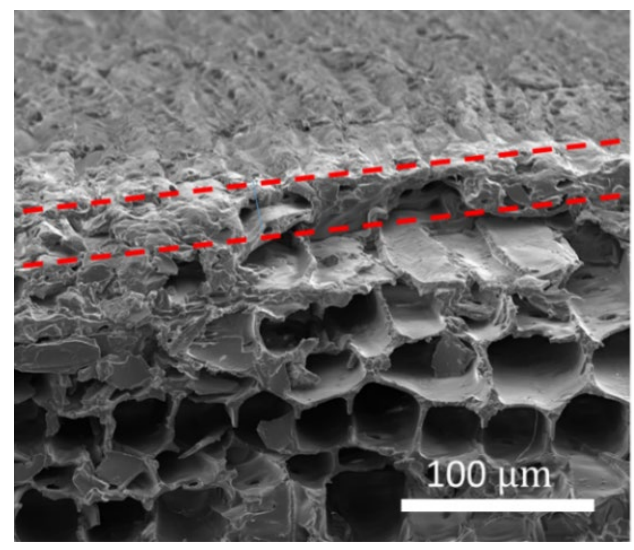

Fig. S1. Cross-sectional SEM image of the engineered tree surface. 


\section{Experimental setup of the evaporation tests}

To evaluate the water evaporation rate of the engineered trees, individual trees were fixed on a pre-templated styrofoam with a controlled spacing of $0.5 \mathrm{~cm}$ between the trees. A $3.5 \% \mathrm{NaCl}$ solution was used as the feed solution to mimic the seawater salinity. In a separate test, $\mathrm{NaCl}$ solutions with different concentration (up to 15\%) were prepared as the feed water. The trees-loaded Styrofoam was floating on the feed water reservoir with a volume of 2 liters, of which the concentration change was typically less than $10 \%$ during the tests. Solar irradiation was provided on the top of the engineered tree lattice using a solar simulator (Newport Oriel 69907). The solar intensity on the top surface of tree was measured and controlled at $1000 \mathrm{~W} / \mathrm{m}^{2}$ using a power meter (Newport, 1916-R). The temperature of the bulk water and the tree surface was measured using a thermocouple (Omega $\mathrm{HH} 74 \mathrm{~K}$ ). The water evaporation rate was calculated based on the mass change of the feed water reservoir and the floating engineered tree lattice measured by an electronic balance (Cotizen CX301) with an accuracy of $0.1 \mathrm{mg}$. Since the Styrofoam was trimmed to match the surface area of the feed water reservoir, evaporation from the feed water was negligible. 


\section{Comsol Multiphysics Model}

The thermodynamic properties and transport of water vapor (relative humidity, $\phi$ ) can be described using mixture laws, and by summing the mass conservation equations for vapor and liquid water, the time-dependent evolution of moisture content can be written as

$$
\frac{\partial W(\phi)}{\partial t}+\rho_{g} \boldsymbol{U}_{\boldsymbol{g}} \cdot \nabla \theta_{v}+\nabla \rho_{l} \cdot \boldsymbol{U}_{\boldsymbol{l}}+\nabla \cdot \boldsymbol{V}_{\boldsymbol{w}}+\nabla \cdot \boldsymbol{V}_{\boldsymbol{l}}=0
$$

with $\rho_{g}$ the density of moist air, $\rho_{l}$ the density of liquid water, and the mass vapor fraction $\theta_{v}$ defined as:

$$
\theta_{v}=\frac{M_{v} \phi C_{s a t}(T)}{\rho_{g}}
$$

where $M_{v}$ is the total mass of vapor and $C_{s a t}(T)$ is the saturation vapor concentration at a given temperature $T$.

The convection of the liquid water with flow field $\boldsymbol{U}_{\boldsymbol{l}}$ was computed by Darcy's law and the convection of vapor with flow field $\boldsymbol{U}_{\boldsymbol{g}}$ was computed by the Brinkman equation. The last two terms of Eq. S1 describe (i) the binary diffusion of water vapor and dry air in the gaseous phase, with $\boldsymbol{V}_{\boldsymbol{w}}$ defined as:

$$
\boldsymbol{V}_{w}=-\rho_{g} D_{g} \nabla \theta_{v}
$$

and (ii) the capillary transport of liquid water, with $\boldsymbol{V}_{\boldsymbol{l}}$ defined as:

$$
\boldsymbol{V}_{\boldsymbol{l}}=-D_{w} \frac{\partial W(\phi)}{\partial \phi} \nabla \phi
$$

where $D_{g}$ and $D_{w}$ are the diffusion coefficients of vapor and liquid water, respectively. 
Table S1. Parameters used in the COMSOL model.

\begin{tabular}{|l|l|}
\hline Parameters & Value $[\mathrm{Unit}]$ \\
\hline Ambient pressure & $1[$ atm $]$ \\
\hline Ambient temperature & $293.15[\mathrm{~K}]$ \\
\hline Molecular weight of air & $0.028[\mathrm{~kg} / \mathrm{mol}]$ \\
\hline Air viscosity & $1.81 \times 10^{-5}\left[\mathrm{~kg} /\left(\mathrm{m}^{*} \mathrm{~s}\right)\right]$ \\
\hline Air thermal conductivity & $0.025\left[\mathrm{~W} /\left(\mathrm{m}^{\star} \mathrm{K}\right)\right]$ \\
\hline Air heat capacity & $1.006 \times 10^{3}\left[\mathrm{~J} /\left(\mathrm{kg}{ }^{*} \mathrm{~K}\right)\right]$ \\
\hline Air density & $1.205\left[\mathrm{~kg} / \mathrm{m}^{\wedge} 3\right]$ \\
\hline Air-vapor diffusivity & $2.6 \times 10^{-5}\left[\mathrm{~m}^{\wedge} 2 / \mathrm{s}\right]$ \\
\hline Viscosity of water & $1.002 \times 10^{-3}\left[\mathrm{~kg} /\left(\mathrm{m}^{*} \mathrm{~s}\right)\right]$ \\
\hline Thermal conductivity of water & $0.59\left[\mathrm{~W} /\left(\mathrm{m}^{*} \mathrm{~K}\right)\right]$ \\
\hline Heat capacity of water & $4.182 \times 10^{3}\left[\mathrm{~J} /\left(\mathrm{kg}{ }^{\star} \mathrm{K}\right)\right]$ \\
\hline Density of water & $998.2\left[\mathrm{~kg} / \mathrm{m}^{\wedge} 3\right]$ \\
\hline Vapor heat capacity & $0.026\left[\mathrm{~W} /\left(\mathrm{m}^{*} \mathrm{~K}\right)\right]$ \\
\hline Vapor viscosity & $1.8 \times 10^{-5}\left[\mathrm{~kg} /\left(\mathrm{m}^{*} \mathrm{~s}\right)\right]$ \\
\hline Vapor thermal conductivity & $2.062 \times 10^{3}\left[\mathrm{~J} /\left(\mathrm{kg}{ }^{*} \mathrm{~K}\right)\right]$ \\
\hline Wood porosity & 0.5 \\
\hline Wood permeability & $1 \times 10^{-14}\left[\mathrm{~m}^{\wedge} 2\right]^{1}$ \\
\hline Wood thermal conductivity & $0.21\left[\mathrm{~W} /\left(\mathrm{m}^{*} \mathrm{~K}\right)\right]^{2}$ \\
\hline Wood heat capacity & $1650\left[\mathrm{~J} /\left(\mathrm{kg}{ }^{*} \mathrm{~K}\right)\right]^{2}$ \\
\hline Wood density & $420\left[\mathrm{~kg} / \mathrm{m}^{\wedge} 3\right]$ \\
\hline
\end{tabular}

\section{Predicting evaporation rate using meteorological data.}

The temperature-dependent latent heat of vaporization, $L(T)$ and the vapor pressure, $P(T)$ were computed as:

$$
L(T)=-0.00006 T_{\text {surface }}{ }^{3}+0.0016 T_{\text {surface }}{ }^{2}-2.36 T_{\text {surface }}+2500.8
$$




$$
\log P(T)=8.07131-\frac{1730.63}{233.426+T}
$$

The heat transfer coefficient $h c$ of a vertical cylinder was defined as

$$
h c=\frac{k}{\lambda}\left(0.68+\frac{0.670 R a^{1 / 4}}{\left[1+(0.492 / \mathrm{Pr})^{\frac{9}{16}}\right]^{4 / 9}}\right)
$$

with $k$ the thermal conductivity of air, and $\lambda$ the characteristic length of a single engineered tree. The Rayleigh number $(\mathrm{Ra})$ was further defined as the product of Prandtl number (Pr) and Grashof number (Gr), which are expressed as

$$
\begin{aligned}
& \operatorname{Pr}=v / \alpha \\
& G r=g \lambda^{3} \epsilon\left(T_{\text {air }}-T_{\text {surface }}\right) / v^{2}
\end{aligned}
$$

where $v, \alpha$ and $\epsilon$ are the kinematic viscosity, the thermal diffusivity, and the expansion coefficient of air, respectively.

The daily maximum and minimum temperature and relative humidity at the selected modeling regions were collected from the Global Historical Climatology Network-Daily Database ${ }^{3}$ and US Climate Reference Network ${ }^{4}$ under National Climatic Data Center. The daily climate data was then processed to simulate the hourly data by assuming they follow a sinusoidal pattern:

$$
\begin{aligned}
& T(t)=\left(T_{\text {max }}-T_{\text {min }}\right) * \sin \left(\frac{\pi}{12} * t-\frac{2 \pi}{3}\right)+T_{A v g} \\
& R H(t)=\left(R H_{\text {max }}-R H_{\text {min }}\right) * \sin \left(\frac{\pi}{12} * t+\frac{\pi}{4}\right)+T_{A v g}
\end{aligned}
$$

Lastly, the solar irradiation I was simulated using the Bird Clear Sky Model. ${ }^{5}$ We solved for the surface temperature using an iterative method. The value of $T_{\text {surface }}$ started from 
the ambient air temperature, and reduced by $0.1^{\circ} \mathrm{C}$ in each step, until the energy balance was reached.

\section{Calculating the solid-liquid adhesion energy}

The adhesive energy between the engineered tree and liquid water was calculated using the Young-Dupre equation ${ }^{6}$ :

$$
W_{S L}=\gamma_{L G}(1+\cos \theta)
$$

with $\gamma_{L G}$ the surface tension of the liquid-gas interface and does not change with the properties of the solid phase. Comparing the water contact angle change after and before the delignification treatment led to a ratio of 1.5 in the adhesion energy.

\section{Stability test of water vapor generation}

The mass of water vapor generation from natural wood and the engineered tree was monitored for 20 hours. The water evaporation rate from natural wood decreased gradually in the first 10 hours due to the insufficient supply of feed water to the evaporative surfaces. We also observed gradual dehydration of the natural wood surface. The evaporation rate from the engineered tree was almost constant.

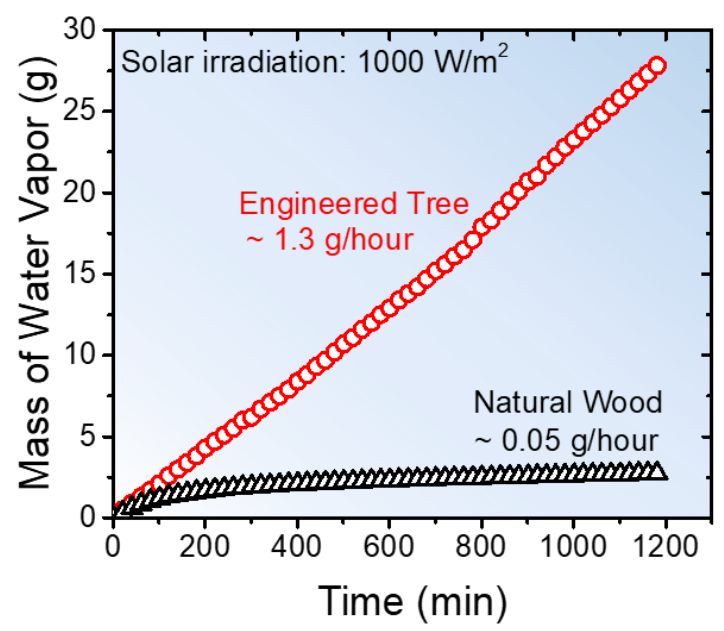

Fig. S2. Water vapor generation rate under one-sun irradiation for 20 hours. 
The surface temperature of the engineered tree in the dark condition

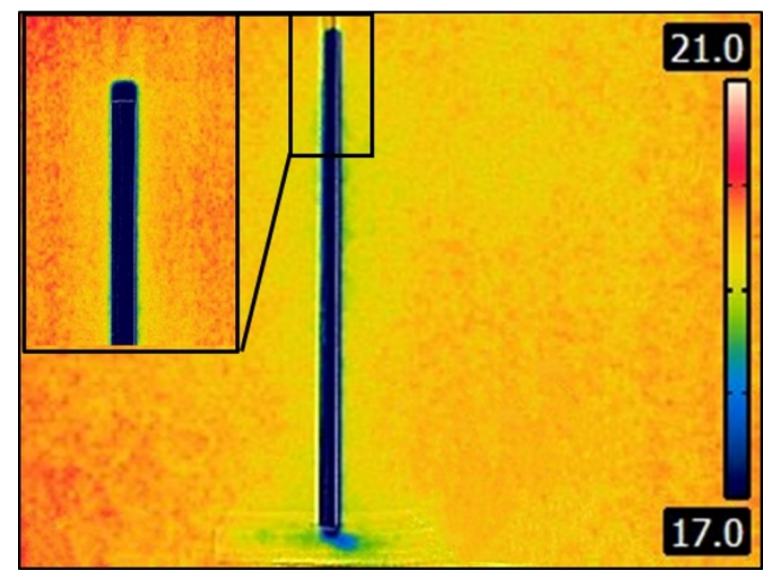

Fig. S3. Thermal image of the engineered tree in the dark condition

\section{Estimating the energy contribution from diffusive light}

Due to the light scattering, the side surfaces of the engineered trees received a significant amount of solar energy as well (Figure S4a). To estimate such energy, a light-reflecting panel was installed so that only the top surface of the engineered tree was expose to direct solar radiation (Figure S4b). We also used nonreflecting material to minimize any light scatter from the surrounding objects. The evaporation rate dropped around 0.3 $\mathrm{g} /$ hour after eliminating the adsorption of diffusive light. The loss of the energy was then calculated to be $0.2 \mathrm{~W}$ by multiplying the latent heat of vaporization (i.e., $2460 \mathrm{~J} \cdot \mathrm{g}^{-1}$ ).
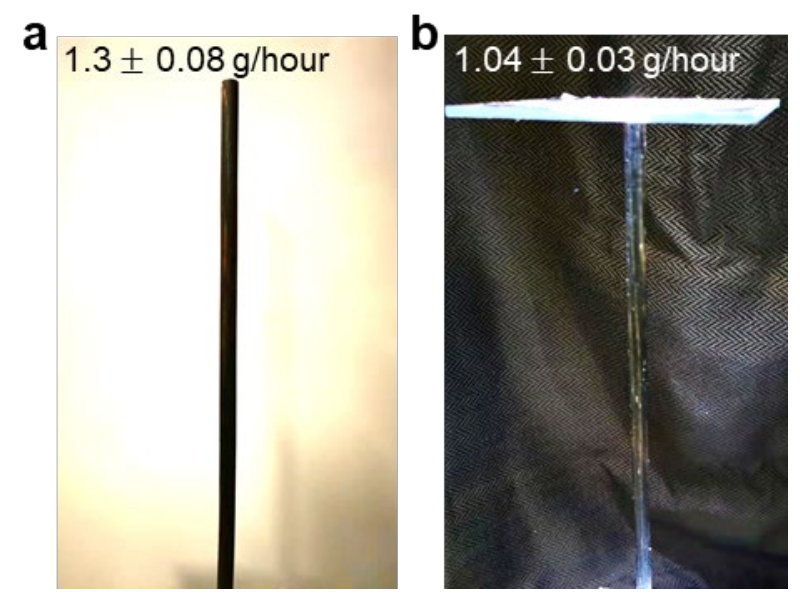

Fig. S4. Digital image of the engineered tree (a) without, and (b) with the light-reflecting panel. 


\section{Decouple the energy contribution under different solar irradiation}

The evaporation rate under different light intensity was measured and is shown in Fig. 3d. The total amount of energy for vaporization was hence calculated accordingly. Since the energy contributions from the direct and diffusive light depend on the power of the light source, we assumed that these two contributors correlate linearly with the applied solar intensity. The remainder of the energy was then attributed to the contribution of ambient heat, which stayed almost constant because the surface and air temperature barely changed when reducing the power of the solar simulator.

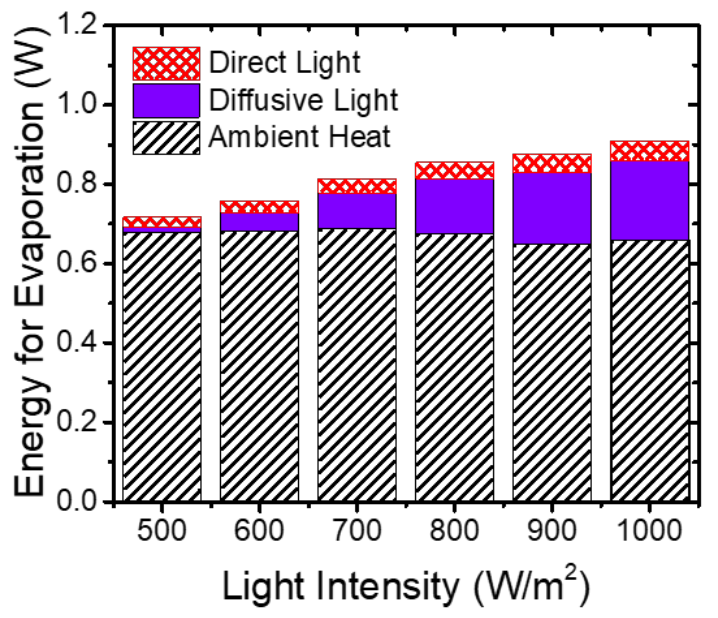

Fig. S5. Evaluating energy contribution from different sources. 


\section{Simulating heat transfer in the engineered tree lattice}

COMSOL Multiphasic was used to simulate the temperature distribution within the engineered tree lattice. The diffusive flux of enthalpy of vaporization, and the heat transfer associated with capillary flux, due to the presence of the liquid water in the pores, are included in the following heat source term on the right side of the equation:

$$
Q=-\left[\left(C_{p v}-C_{p a}\right) \boldsymbol{V}_{w}+C_{p l} \boldsymbol{V}_{l}\right]
$$

where $C_{p v}, C_{p a}$, and $C_{p l}$ are the heat capacity of water vapor, air and water, respectively. Detailed definition of the binary diffusion of water vapor and dry air in the gaseous phase $V_{w}$, and the capillary transport of liquid water $V_{l}$ can be found in the Materials and Methods. The heat of evaporation is used as the source term in the heat transfer equation

$$
Q_{\text {evap }}=E \times L
$$

where $L$ is latent heat of vaporization and $E$ is the evaporation rate. The distance between the trees was set to be $0.5 \mathrm{~cm}$. Initial temperature of the air was $293 \mathrm{~K}$. The convective airflow from left to the right was set to be $0.1 \mathrm{~m} / \mathrm{s}$.

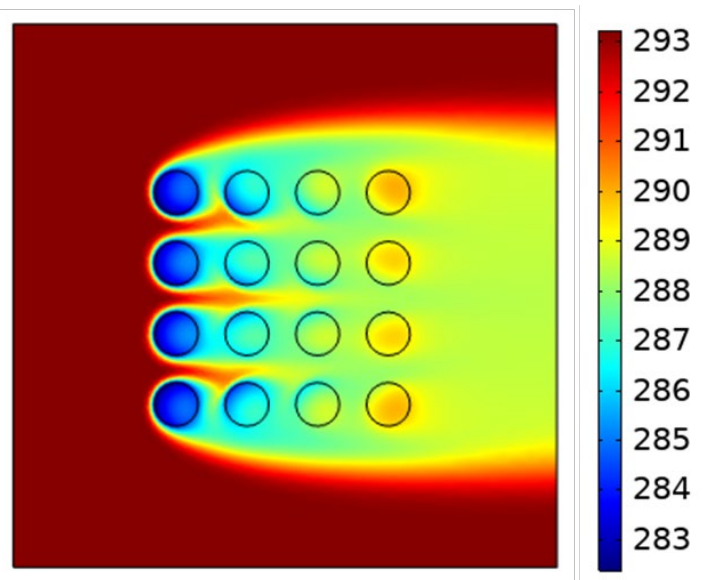

Fig. S6. Simulated temperature distribution (in Kelvin) in the engineered tree lattice. 


\section{Calculating the LAl of the engineered tree lattice}

The LAI was calculated as the ratio of evaporative surface area and the ground area:

$$
L A I=\frac{76 n^{2}}{[0.8 n+G(n-1)]^{2}}
$$

where $\mathrm{n}$ is the number of engineered trees in one row and $G$ is the gap size. When $G$ is fixed at $0.5 \mathrm{~cm}$, the LAI approaches to a limit of 45 (Fig. S7a). For a $4 \times 4$ system, the change of LAl is shown in Fig. S7b.
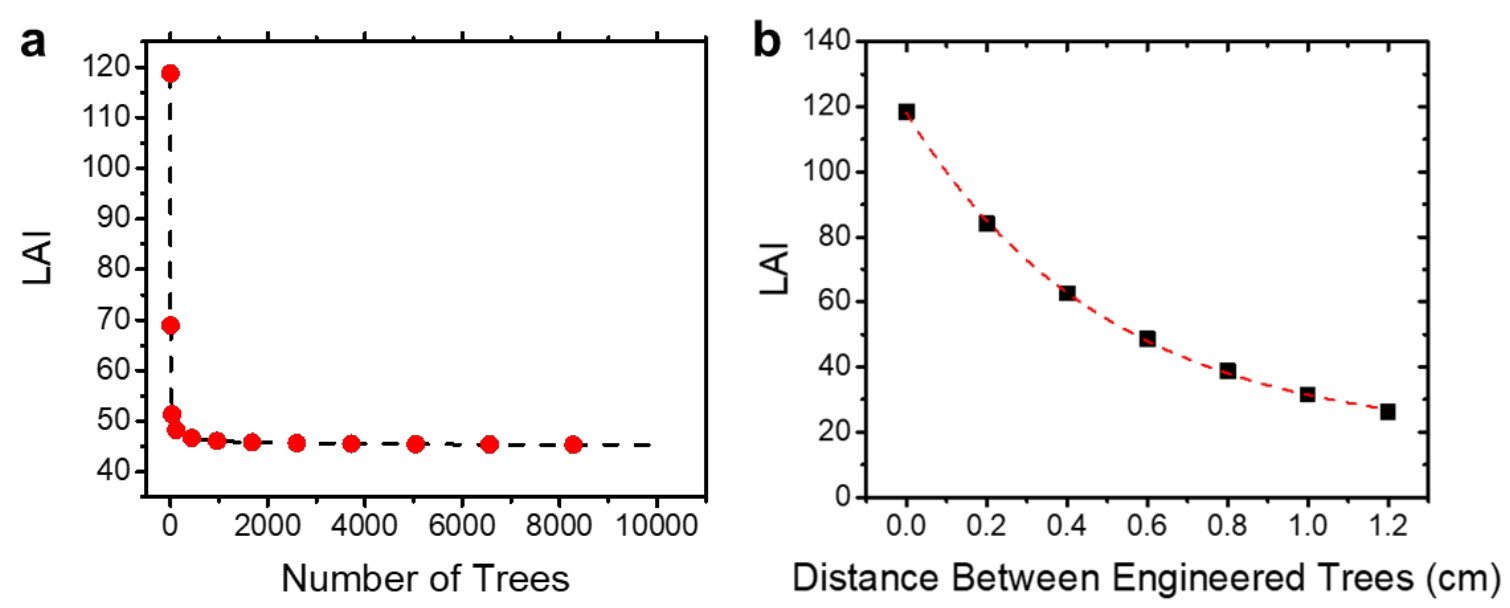

Fig. S7. Effect of the number of trees (a) and the gap size (b) on the LAl of engineered tree lattice.

\section{Prediction of evaporation rate in a large scale engineered tree system}

The water evaporation rate of the engineered trees lattice was model fitted using an exponential decay formula, and extrapolated to estimate the evaporation for a more significant number of engineered trees. To validate the accuracy of the prediction, an $8 \times 8$ system was tested. The evaporation rate was found to be $4.67 \pm 0.39 \mathrm{LMH}$, close to 4.64 as predicted by model extrapolation. 


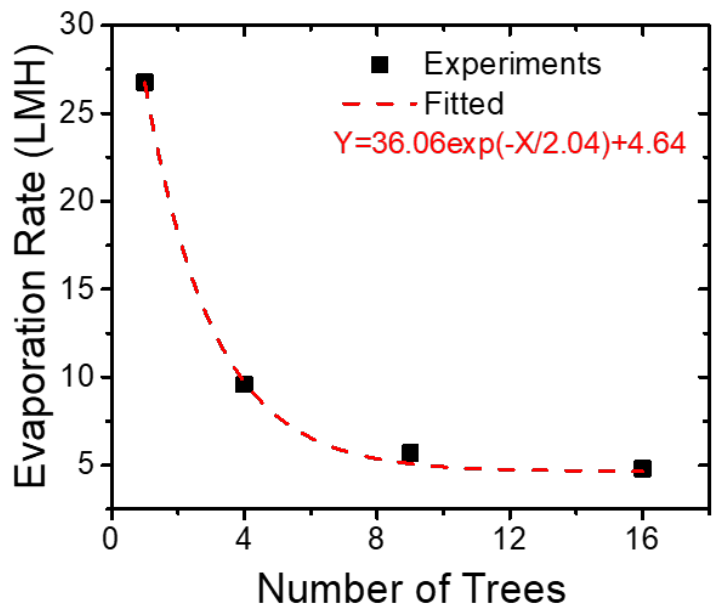

Fig. S8. Decline trend of evaporation rate as system scale-up.

\section{Desalination performance under the different operation modes}

Water vapor generation rate was tested under two different modes using $3.5 \mathrm{wt} \% \mathrm{NaCl}$ solution as the feed water. During the first test, the engineered trees were exposed to one-sun irradiation for 24 hours straight. The evaporation rate kept constant at $4.88 \mathrm{LMH}$ (Fig. S8). For the second test, the solar simulator was running for 12 hours and then was shut down. The evaporation rate was monitored for another 12 hours in dark condition. The evaporation rate dropped immediately and then remained constant at $2.87 \mathrm{LMH}$.

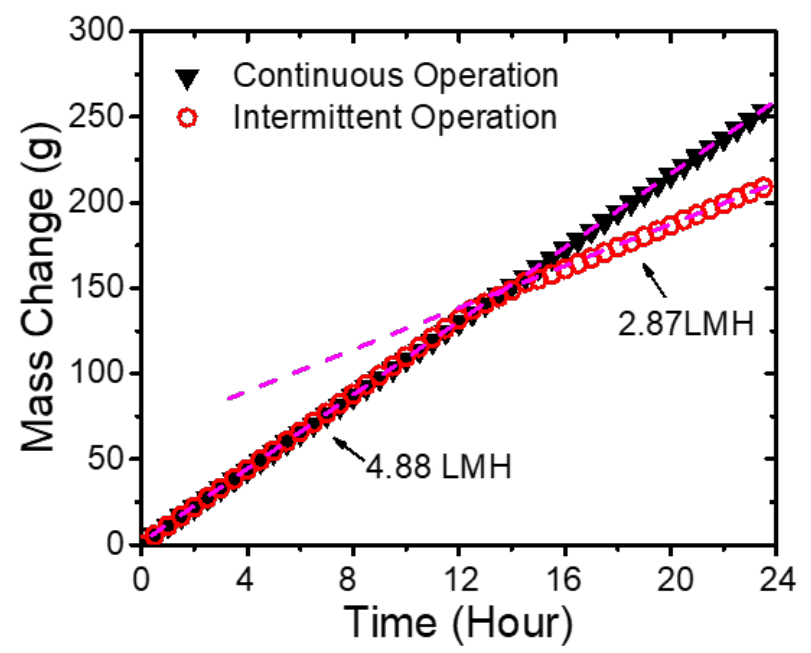

Fig. S9. Water vapor generation under the different operation mode. 


\section{Measuring evaporation rate of different feed water}

$\mathrm{NaCl}$ solutions with different concentrations were prepared to represent the typical salinity of different water sources. Water evaporation rate was measured under one-sun irradiation and in dark condition.

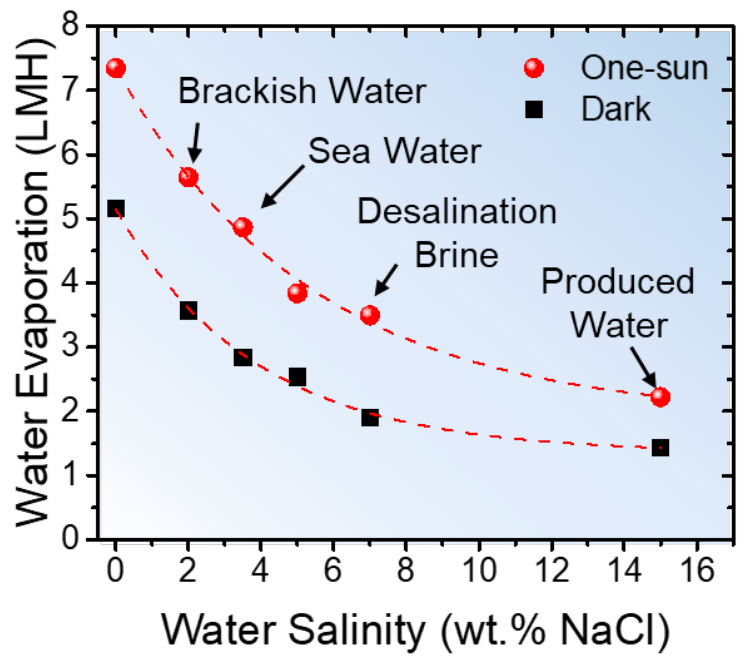

Fig. S10. Water vapor generation under different salinity.

Pilot-scale engineered tree system

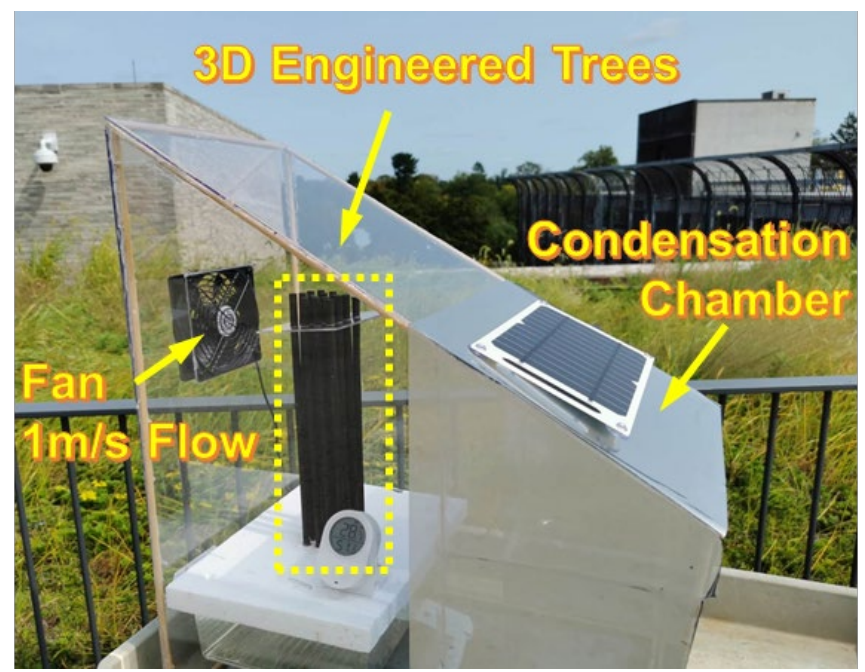

Fig. S11. Digital image of the pilot-scale water vapor generation and collection system. 


\section{Monitoring the climate data during field tests}

Field tests were carried out on the rooftop of Andlinger center in Princeton University (Lat: 40.35, Long: 74.65$)$. The climate data including solar radiation, temperature, and relative humidity were monitored. The solar radiation peaked at around 12 PM with the highest radiation of $800 \mathrm{~W} / \mathrm{m}^{2}$. The temperature lag was about 3 hours. The surface of the engineered trees was $3^{\circ} \mathrm{C}$ to $5^{\circ} \mathrm{C}$ cooler than the ambient air temperature. The relative humidity was mainly affected by the air temperature because the saturation vapor pressure (i.e., the ability for air to carry water vapor) increases with the air temperature.

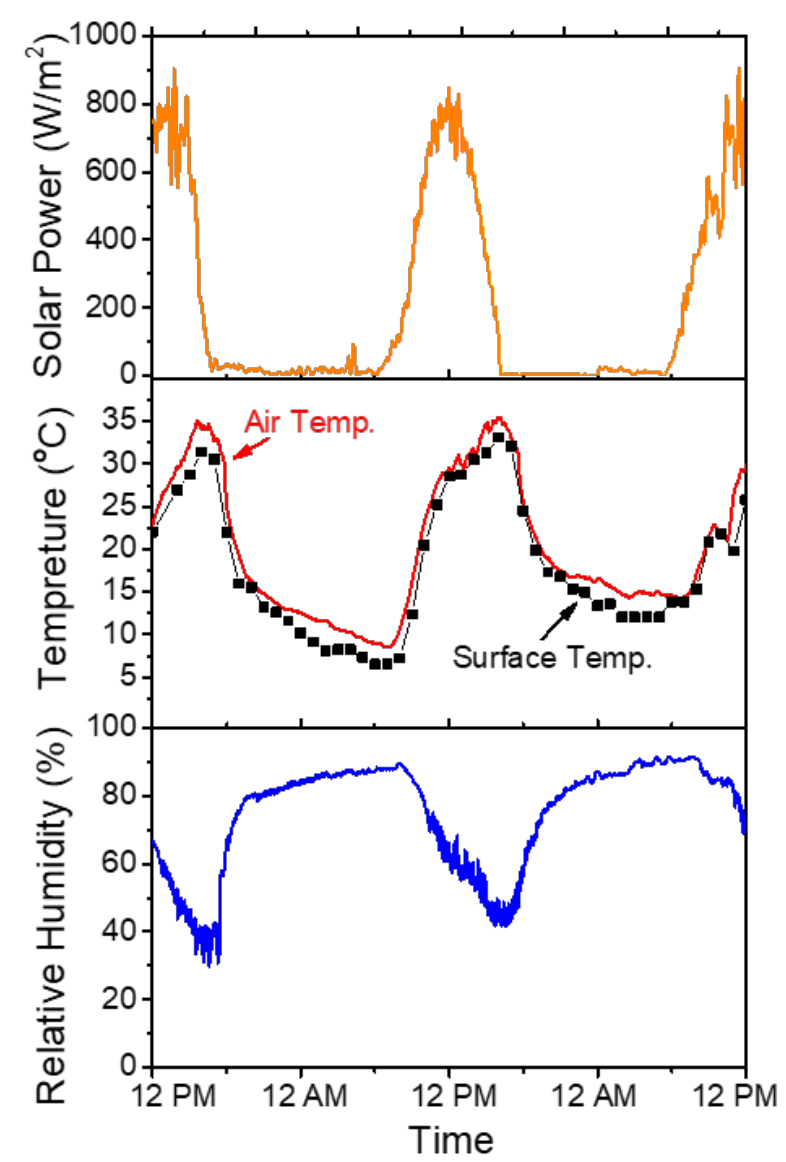

Fig. S12. Climate data during a two-day test. 


\section{Salt precipitation and self-cleaning during field tests}

The outdoor pilot tests were performed using $3.5 \% \mathrm{NaCl}$ solution as the feed water. The convective salt flux was calculated based on the evaporation rate assuming the bulk concentration had minor change ( $\sim 5 \%$ in two days). The diffusive salt flux was calculated by monitoring the conductivity of the feed solution, which converted to the concentration change.
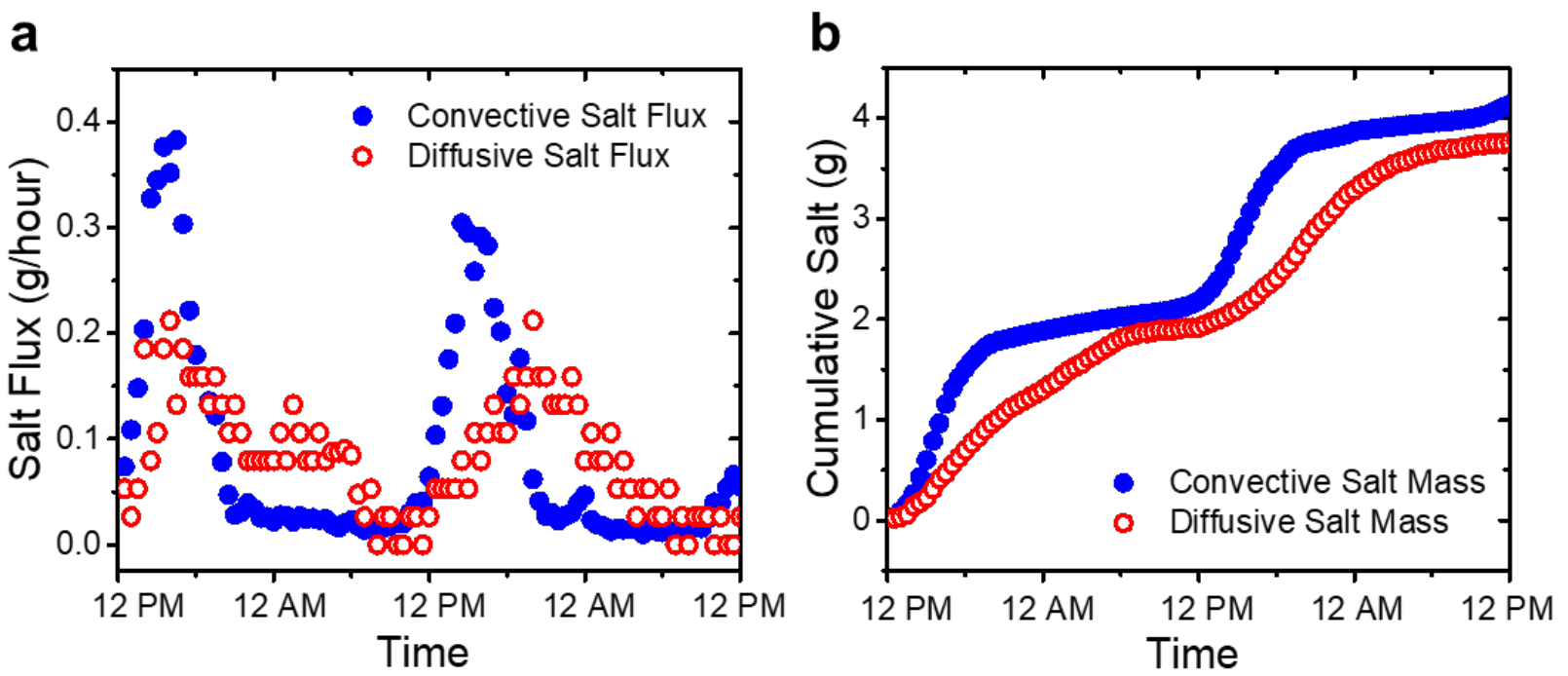

Fig. S13. Salt flux (a) and the cumulative salt balance (b) of a $4 \times 4$ engineered tree lattice during outdoor pilot test. 


\section{Model validation analysis}
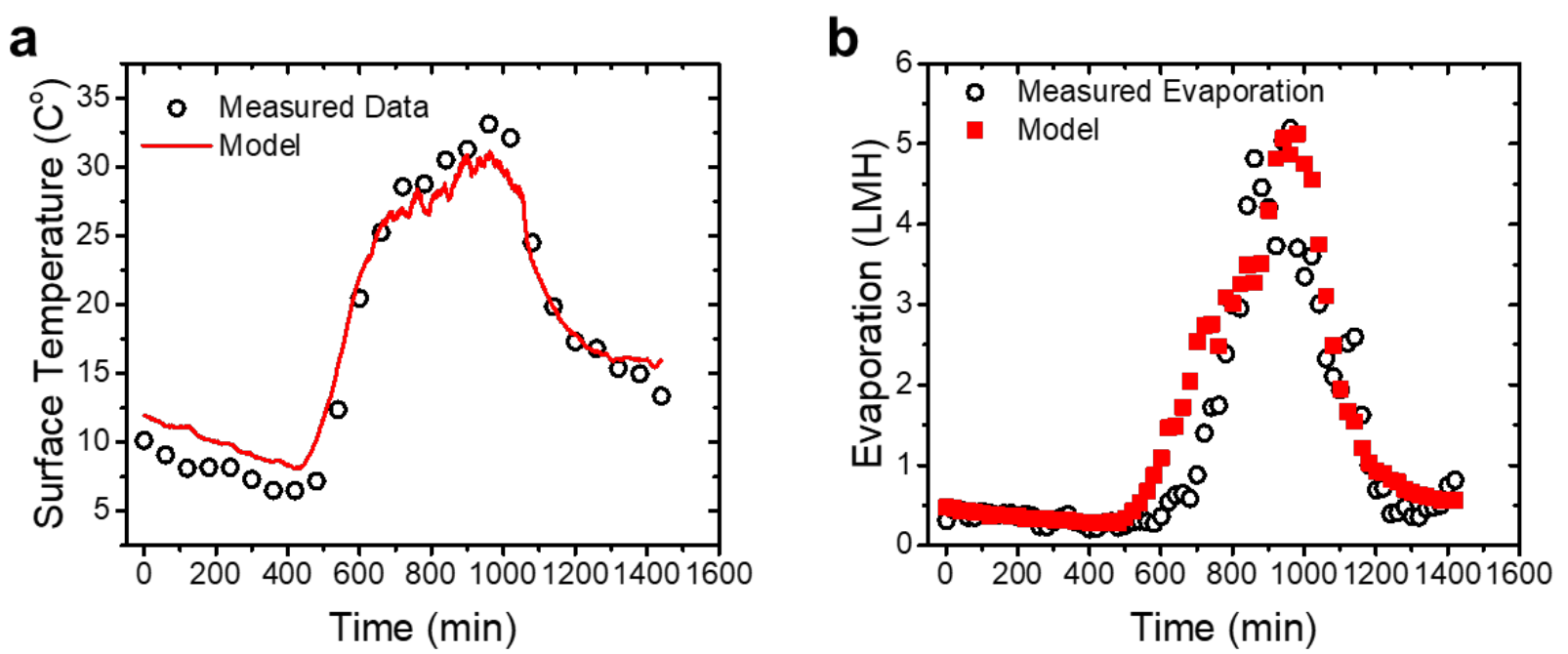

Fig. S14. Comparison between measured data and the model results.

\section{References}

1. Jia, C.; Li, Y.; Yang, Z.; Chen, G.; Yao, Y.; Jiang, F.; Kuang, Y.; Pastel, G.; Xie, H.; Yang, B.; Das, S.; Hu, L., Rich Mesostructures Derived from Natural Woods for Solar Steam Generation. Joule 2017, 1, (3), 588-599.

2. $\quad$ Li, T.; Liu, H.; Zhao, X.; Chen, G.; Dai, J.; Pastel, G.; Jia, C.; Chen, C.; Hitz, E.; Siddhartha, D.; Yang, R.; Hu, L., Scalable and Highly Efficient Mesoporous Wood-Based Solar Steam Generation Device: Localized Heat, Rapid Water Transport. Advanced Functional Materials 2018, 28, (16), 1707134.

3. Menne, M. J.; Durre, I.; Vose, R. S.; Gleason, B. E.; Houston, T. G., An Overview of the Global Historical Climatology Network-Daily Database. Journal of Atmospheric and Oceanic Technology 2012, 29, (7), 897-910.

4. Diamond, H. J.; Karl, T. R.; Palecki, M. A.; Baker, C. B.; Bell, J. E.; Leeper, R. D.; Easterling, D. R.; Lawrimore, J. H.; Meyers, T. P.; Helfert, M. R.; Goodge, G.; Thorne, P. W., U.S. Climate Reference Network after One Decade of Operations: Status and Assessment. Bulletin of the American Meteorological Society 2013, 94, (4), 485-498.

5. Bird, R. E.; Hulstrom, R. L. Simplified clear sky model for direct and diffuse insolation on horizontal surfaces; Solar Energy Research Inst., Golden, CO (USA): 1981.

6. Schrader, M. E., Young-dupre revisited. Langmuir 1995, 11, (9), 3585-3589. 